\title{
Analysis of Development of Curriculum System for Electrical and Mechanical Professions
}

\author{
Miao Shang ${ }^{1, a^{*}}$ and Jiabin $\mathrm{Li}^{2, \mathrm{~b}}$ \\ ${ }^{1}$ Mechanical and electrical technology, Xijing University, Xi'an, China \\ ${ }^{2}$ Mechanical and electrical technology, Xijing University, Xi'an, China \\ a445700839@qq.com, b316404239@qq.com \\ *The corresponding author
}

Keywords: Mechanical and electrical professional; Higher vocational education; Curriculum system; Training plan; Project teaching

\begin{abstract}
The macroscopic education theory and micro teaching practice are connected through the course. Education theory, education idea, education ideology and training target, these can achieve must be with the help of course. The research of curriculum system is of great significance for correct understanding of the development direction of higher vocational curriculum system in our country. In this article, the curriculum system are introduced for mechanical and electrical major in higher vocational colleges; The development and characteristics of the curriculum system are analyzed for major of higher vocational education abroad, and the major development and characteristics of the curriculum system are described for major of higher vocational education. Finally pointed out that the research of curriculum system is closely related to the talent cultivation of higher vocational students for mechanical and electrical major in higher vocational colleges, and the course system establishment needs to accord with our country education development direction. The research of mechanical and electrical professional curriculum system is of great significance for the long-term development of higher vocational colleges and training mode of higher vocational students in our country.
\end{abstract}

\section{Introduction}

Higher vocational education is different from technical secondary school, technical school. Such as secondary vocational and technical education, which embodied in the education should have the corresponding cultural theory base and knowledge base vocational education different from ordinary education subject sex education, and that embodied in the curriculum on the professional characteristics of" technical "distinction between education and academic education, embodied in the theory with practice, reality get to work, the ability to solve the problem [1]. Course communication with macro education theory and micro teaching practice, education theory, education ideology, the concept of education and training objectives, must, in the course to gain. Therefore higher vocational electrical and mechanical professional course system of research is of great significance to correctly identify the direction of higher vocational curriculum system development in our country. Curriculum system of mechanical and electrical professional includes basic course class skills courses, and curriculum system is shown in figure 1.1 .

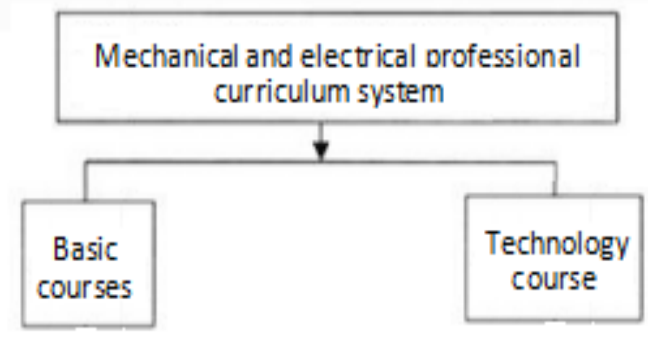

Figure 1. Curriculum system of mechanical and electrical professional 


\section{Curriculum System Development and Characteristics of Abroad}

The developed countries for the development of vocational education curriculum system originated in the ordinary higher education subject systematic curriculum pattern, after analysis "career guidance" and "learning theory", which is currently in development trend of "working process oriented" model [2]. Throughout history, the western developed countries of higher vocational education mainly has six kinds of typical model of curriculum. The six kinds of typical model of curriculum.

CBE Course System Model. The course design of the scheme of modular attaches great importance to the students' ability training, for student assessment is required to engaged in a professional capacity for the standard, the proportion of theory and practice class is about 1:1. CBE course system using dacum method, its development through job analysis, task analysis, teaching analysis, development and implementation of five links.

Dual System Curriculum System Model. The dual system curriculum system of the curriculum standard regulations including training and the teaching plan outline of two parts, the enterprise is responsible for the complete training regulations, standards, vocational school is responsible for the complete teaching plan outline standards, collaboration between both sides, common to complete the curriculum standards [3]. "Dual system" curriculum system is a system, scientific job analysis as the foundation of development, through the curriculum standards, curriculum structure design two development steps.

Career Developmental Course System Model. Career developmental curriculum system model of core characteristics professional development of each industry is divided into stage introduction, technology, special period stage, administration and research five longitudinal coherent phase, and then according to the characters of each stage the talent they need for planning a curriculum system. At the same time, it should be pointed out that every stage of the career development needs of professional knowledge, ability and technology, that has a spiral structure relationship, therefore, that can be used in a cycle of gradual way to prepare the course content, make different students can choose according to their own ability and the demand of different learning styles: after a certain stage of the course directly to enter the job market or into the next study stage, to a higher level of learning.

MES Course System Model. Been translated into "module type professional skills from the model" of MES is one of the research and development by the international Labor organization modular Skill set curriculum [4]. First of all, the nature of the event and tasks according to the classification of human economic activity is divided into a number of professional field; Secondly, according to each class people are engaged in production activities within the territory of working conditions, working environment, and the relationship between the career field will be divided into several work scope; Again, to a certain scope of work shall be carried out in accordance with the activities, tasks, and then the properties of dividing into several work; And the producers must possess the skills to finish a work standard, namely the professional skill system, MES is a copy of this profession system actually [5]. Skills or process standards can be divided into several objects, according to the nature of the active object or activity order divided into several units.

Course System Model Professional Cluster. Group as a professional as prepare the logical starting point of professional cluster course mode, its core purpose is to improve graduates employment flexibility and adaptability, the main course structure is divided into a pyramid cluster structure and parallel type cluster course structure. The former refers to the students in the early stages of learning and extensive learning a professional group of the required knowledge and skills together, and then according to individual ability and vocational interest in further study gradually narrowing the scope of study, will eventually learn range from the professional group to a particular profession; The latter mainly refers to the students in required to complete a professional group of the study of common knowledge and skills, to study their introduction to the various professional technology widely [6]. 
Integrate Type Course System Model. Integration of vocational education curriculum pattern according to the divided into science and technology integration and its integration content integration cluster ladder type. Core objective is to cultivate technical talents of the former, so the need for interdisciplinary system integration technology; The latter based on the student career development stage characteristic, comprehensive professional cluster type and ladder type curriculum system, the advantages of two kinds of curriculum system for students as a cluster of points stage education: students, first of all, accept professional group of initial education, so as to determine their own target professional group, in the learning objectives professional group of shunt after the common knowledge and skills required to accept different categories of basic education, professional specialization education, in turn, to accept a particular career.

\section{Development and Characteristics of the Course System in Our Country}

The curriculum reform and curriculum system shows the characteristics of periodic pattern evolution: the first is in the beginning of establishing imitate common subject curriculum system in colleges and universities; The second is in the early $1990 \mathrm{~s}$, some developed areas in higher vocational colleges actively introduce and practice of the course system of western developed countries, and on the basis of these course system development ideas, to develop platform, with a strong taste of local module type, wide basis living module cluster type, curriculum system integrating, etc.

Platform Course System Model. Platform course system model is widening specialty caliber as the goal layer constructing curriculum system [7]. Common platform of curriculum system is divided into "three-level platform" and "four platform" two modes. Public lesson foundation platform by increasing the humanities and social science and on course to broaden subject foundation of quality education. Categories of professional basic course through integration and reorganization of several professional foundation courses, thus forming a unified categories of professional basic course group. Professional or professional direction course platform through part of a professional course, the formation of several available for students elective course or professional direction class group. Platform course system mode pays attention to the cultivation of the students' career development and job migration ability. So the platform are set up compulsory courses and elective courses, to enhance students choose course of flexibility.

Modular Curriculum System Model. Modular curriculum system model including the subject knowledge and professional ability system two parts. Among them, the subject knowledge point to the moral education classes, cultural classes and some theoretical knowledge such as humanities and science courses teaching module; Professional ability system corresponding to the professional or post group of necessary professional ability and professional technology [8]. Knowledge system and ability system is interconnected and independent of each other. Under the guidance of teachers, students according to their own career planning choose to suit oneself professional knowledge and ability of direction and position module to study.

Subject Curriculum System Model. Systematic curriculum system including the theory course and practice course two big modules. The core characteristic of this model is focuses on the learning of basic knowledge of culture. Practical curriculum system only as extension and complement of theory course, independent of the theory courses [9]. Subject systematic curriculum system based on subjects as the logical starting point according to the course content order phased array. Subject systematic curriculum system to develop specific process for: from the strict discipline logic knowledge system, select the right and according to the actual situation of the education object to the content of the simplified, and then according to the knowledge content of the order. Core characteristic is attaches great importance to the basic knowledge of culture learning, pay equal attention to theory course and practice course, practice course as a complement of theory course.

Project Curriculum Model. Since this century, some colleges and universities has formed a new curriculum system. These systems based on the work demand, formed in the framework of working structure, vocational ability as the goal, the working process of the task as the background, the situation 
as the center, project curriculum courses throughout the project. Project curriculum system has broken the discipline curriculum systematic curriculum system [10]. Course content and the connection between the workforce is outstanding. Students form the working in the complex situation of judgment and problem solving skills, and students' comprehensive vocational ability is improved. The project subject curriculum system as the direction of the reform of vocational education curriculum system. At present academic circles the research of project curriculum system has not break through the bottleneck. This is mainly manifested in two aspects: on the one hand, in the course of reform of vocational education project also imprisoned in partial reforms, stay in a small range of specific project curriculum development, not from the perspective of curriculum system to build the whole project to consider the whole course project design; When setting specific projects, on the other hand, is not according to the working need to set up the project, but with good capture, project execution for selection basis, project professional, pertinence is not strong, low technical content.

\section{Conclusion}

Higher vocational and technical education is embodied in the curriculum of vocational characteristics, and it is embodied in the embodied in the theory with practice, reality get to work, the ability to solve the problem. In this article, the curriculum system are introduced for mechanical and electrical major in higher vocational colleges; the development and characteristics of the curriculum system are analyzed for major of higher vocational education abroad, and the major development and characteristics of the curriculum system are described for major of higher vocational education. Finally pointed out that the research of curriculum system is closely related to the talent cultivation of higher vocational students for mechanical and electrical major in higher vocational colleges, and the course system establishment needs to accord with our country education development direction. The research of mechanical and electrical professional curriculum system is of great significance for the long-term development of higher vocational colleges and training mode of higher vocational students in our country.

\section{References}

[1]. J.B.Wang, H.T.Yang: New Field of Overseas Investment-New Trend of Transnational Higher Education (DongYue Review, China, 2012)

[2]. Wang Boqing. 2012 Chinese university students' employment report [M]. Beijing: social sciences academic press, 2012:46.

[3]. sichuan Zhou Qin. Higher vocational education curriculum mode and select [D]. Nanjing: nanjing normal university, 2007:15 to 16.

[4]. mei-yun zhang. Tumor disease and reform path of the curriculum in colleges and universities [[J]. Journal of China's higher education, 2010 (17) : 33-34.

[5]. Chen Lanjian. Comprehensive vocational ability orientation of higher vocational curriculum reform research [[D]. Nanjing: nanjing university of science and technology, 2008:20.

[6]. New before the king. "training mode of higher vocational education person diao 'construction M] shantou, shantou university press, 2002:230.

[7]. Huang Kexiao. Introduction to vocational and technical education course [M]. Shanghai: east China normal university press, 2000:136.

[8]. The curriculum system of higher vocational project research [M]. Beijing: Beijing university of science and technology press, 2011:25 to 37.

[9]. Chun Zhou. Jiang machinery innovation ability structure of the system analysis of higher vocational students. School education in China, 2011 (6) : 56-58

[10]. Xiang wei Liu. Based on the working process of the development of higher vocational machinery manufacturing professional curriculum strategy. Education and career, 2011 (11): 138 139. 